\title{
Safety of the Patient from the Medication
}

\author{
Julio Cesar Garcia Casallas \\ Clinical Pharmacology Department, Clínica Universidad de La Sabana, Investigation Group Evidencia Terapéutica, Universidad de \\ La Sabana, Chia 250001, Colombia
}

\begin{abstract}
Currently, more than 7\% of admissions to acute care hospitals are related with AEMs (adverse events to medications). AEMs are the sixth cause of death, causing a cost of over \$5.6 million dollars (USD) per hospital per year. There is an estimate that between $19 \%$ and $23 \%$ of hospitalized patients will have an adverse effect within the first 30 days after being discharged, $14.3 \%$ will be re-admitted and $70 \%$ of these events will be related to a medication prescription. Fortunately, at least $58 \%$ of these AEMs are preventable, since they result from a lack of information on the medication, prescription and dosage errors and from the abuse and underuse of the same. Polymedicated patients, especially the elderly with multiple pathologies and/or chronic patients that need to be admitted into the hospital more frequently, usually to internal medicine, neurology, psychiatry, rehabilitation and intensive care, are precisely the most liable to suffer from medication errors. It must be the objective to aim for the increase in the patient safety standards when it comes to medications.
\end{abstract}

Key words: Medication, patient's safety, pharmacological conciliation, polymedication.

\section{Introduction}

An adverse reaction to medication, according to the WHO (World Health Organization Pharmacovigilance), is defined as: "an undesired harmful reaction that takes place after the administration of a medication in dosages that are commonly used for the human species to prevent, diagnose or treat a disease or to modify a biological function" [1]. This definition implies a causal relation between the event that is not preventable and is unexpected and the medication.

Additionally, an adverse event associated to a medication is defined as "any unfavorable medical situation experienced by a patient". The adverse even must occur during the treatment with a medication at any dosage, although there is not necessarily a cause-effect correlation of the same. Other terms used in literature as synonyms are: adverse experience or suspicion of adverse reaction $[2,3]$.

In the year 2002, the WHO broadened the definition of pharmacovigilance to "a science and activities

Corresponding author: Julio Cesar Garcia Casallas, assistant professor, research fields: polymedication, medication adherence, medication safety, chronic diseases. related to the detection, assessment, understanding and prevention of adverse effects or of any other problems related to medication". When comparing this definition with the one from the year 2001 (WHO Pharmacovigilance), there is no substantial difference between the two of them; however, the inclusion of the term PRM (problem related to medication), which amplifies the functions of pharmacovigilance, is underlined [1].

\section{Problems Related to Medication}

According to the Consensus of Granada, PRMs are defined as "health problems understood as the negative clinical results derived from a pharmacological therapy which, produced by diverse causes, lead to the non-accomplishment of the therapeutic objective, or the appearance of undesirable effects. A health problem is understood as all those issues that require or might require the immediate action on the part of the healthcare provider (including the patient)" [4]. From this term it is possible to deduce that not only the adverse reactions inherent to medications are included in the definition, but also all those problems linked to prescription errors (dosage and errors of frequency), 
linked to the patient (personal characteristics of the patient, non-compliance and self-medication), linked to the medication itself (storage problems, adverse reactions), or linked with a healthcare service (no dispatching of the medication, no access to it) [5]. It is important to stress that the term PRM is more extensive and complete than ARMs (adverse reactions to medications) or AEMs (adverse events to medications) [4]. There are numerous classifications of PRMs; one of them described by Zed et al. [6] which appears referenced next (Table 1).

On the other hand, in 2007, the Consensus of Granada suggested a classification for PRMs (Table 2), and additionally coined the term NRM (negative results associated to medication) [4]. It was defined as the health results of a patient that are inadequate for the objectives of the pharmacological therapy and that are related with the use or failure in the use of medication. According to this definition, PRMs are the cause of NRMs. Additionally, the Consensus classified the NRMs into three categories: safety, effectiveness and necessity (Table 2).

The preoccupation for the harmful effects of medication is not a new topic. However, the tragedy gone through in the 1960s with the use of thalidomide and the phocomelia epidemic in newborn children produced an international sensitization of the potential toxic effects of medication [7]. Several countries, and thereafter the WHO, began the international program for the monitoring of medications and an international center for pharmacovigilance was created.

In the 1990s, a new methodological focus was added

Table 1 Classifications of the problems related to medication (modified) [6].

\begin{tabular}{|l|l|}
\hline Event related to the medication & Definition \\
\hline Adverse reaction to medication & $\begin{array}{l}\text { Any harmful effect, not intended and not desired, produced by a medication that is being used for } \\
\text { prophylaxis, diagnosis or treatment at normal human dosages. It includes all the reactions when } \\
\text { medications are utilized in the proper dosages. They can include abnormal laboratory results. }\end{array}$ \\
\hline Non-treated indication & $\begin{array}{l}\text { Any harmful effect, not intended and not desired, produced by medication as a result of a lack of } \\
\text { treatment for a known indication }\end{array}$ \\
\hline $\begin{array}{l}\text { Selection of inappropriate } \\
\text { medication }\end{array}$ & $\begin{array}{l}\text { Any harmful effect, not intended and not desired, produced by the use of a non-optimal medication } \\
\text { for the treatment of a confirmed indication. }\end{array}$ \\
\hline Sub-therapeutic dosage & $\begin{array}{l}\text { Any harmful effect, not intended and not desired, produced by a medication due to a dosage } \\
\text { administration deficiency or deficiency in the duration of the therapy for a specific indication or } \\
\text { patient. }\end{array}$ \\
\hline Supra-therapeutic dosage & $\begin{array}{l}\text { Any harmful effect, not intended and not desired, of a medication due to an excessive dosage or } \\
\text { excessive duration of the therapy for a specific indication or patient. }\end{array}$ \\
\hline Non-adherence & $\begin{array}{l}\text { Any harmful effect, not intended and not desired, of a medication due to the lack of administration of } \\
\text { the same as prescribed by a healthcare professional. }\end{array}$ \\
\hline No indication & $\begin{array}{l}\text { Any harmful effect, not intended and not desired, of a medication due to its use when there is no clear } \\
\text { indication for it. }\end{array}$ \\
\hline Pharmacological interaction & $\begin{array}{l}\text { Any harmful effect, not intended and not desired, of a medication when it is administered at the same } \\
\text { time with two or more medications. }\end{array}$ \\
\hline Self-medication & $\begin{array}{l}\text { Any harmful effect, not intended and not desired, produced by medication when it is self-medicated } \\
\text { by the patient. }\end{array}$ \\
\hline
\end{tabular}

Table 2 PRM classification [4].

\begin{tabular}{|l|l|}
\hline Categories & Definition \\
\hline Necessity & $\begin{array}{l}\text { Untreated health problem. The patient suffers from a health issue associated to not receiving the necessary } \\
\text { medication. } \\
\text { Unnecessary medication effect. The patient suffers from a health problem because he is prescribed with a } \\
\text { medication he does not need. }\end{array}$ \\
\hline Effectiveness & $\begin{array}{l}\text { Non-quantitative ineffectiveness. The patient suffers from a health problem that is associated to the } \\
\text { non-quantitative ineffectiveness of the medication. } \\
\text { Quantitative ineffectiveness. The patient suffers from a health problem due to the quantitative ineffectiveness of } \\
\text { the medication. }\end{array}$ \\
\hline Safety & $\begin{array}{l}\text { Non-quantitative unsafety. The patient suffers from a health problem because of the non-quantitative unsafety of } \\
\text { a medication. } \\
\text { Quantitative unsafety. The patient suffers from a health issue due to the quantitative unsafety of a medication. }\end{array}$ \\
\hline
\end{tabular}


to pharmacological vigilance and for the first time it was recognized that medications, apart from the intrinsic risk of producing adverse reactions, which is inherent to their consumption, can produce harmful effects due to errors and failures that occur while they are being clinically used [7-11]. In several studies it has been quantified that the adverse effects caused by mistakes account for $19 \sim 56 \%$ of the total detected [12-22]. Manasse, in his article Medication Use in an Imperfect World: Drug Misadventuring as an Issue of Public Policy Stresses the importance of the medication's therapeutic chain when there is a chance that a mistake may be made when prescribing. Likewise, he concludes that the accidents with medication are public health concern whose magnitude cannot be foreseen yet [23].

In the year 1999, the American government launched a plan to decrease by $50 \%$ the medical errors within a 5-year timeframe. This measure was proposed after the release of the report done by the institute of Medicine, National Academy of Sciences in which it was estimated that the number of deaths due to medical errors per year were between 44,000 and 48,000 [24]. Additionally, these errors used to cause one out of 854 deaths in hospitalized patients and one out of 131 deaths in non-hospitalized patients. It was also found that errors in medication were causing adverse events in at least $2 \%$ of hospitalized patients, which produced an increase by 4,700 dollars of the average cost of a hospital stay, which then lead to an annual cost of 2.8 million dollars in centers of reference and an average of 2 billion dollars in the national expenditure [5, 22].

The research done on PRMs has revealed that up to $70 \%$ of them could be prevented; this is really important data that sheds light on the impact PRMs have on the healthcare system and public health that translates into higher costs. This last issue has been evaluated in numerous medical publications; some will be cited next.

Several studies carried out in the United States have researched the adverse events produced by medication and their impact on the hospital costs. The patients who developed adverse effects were hospitalized an average of 1.2 to 3.8 days more than those who did not present any ARMs and the additional intra-hospital costs were between US\$ 2.284 and US\$ 5.640 per patient (year 2000) [5, 25].

Recognizing the epidemiologic and economic impact of the problems related to medications, and the great percentage of preventability, strategies have been developed to reduce the incidence, severity and consequences of said problems.

\section{Pharmacotherapeutic Conciliation}

One of the used strategies is the pharmacovigilance and the other is therapeutic conciliation. This last one initiates with the admission's pharmacological background, continues with the conciliation of the patient's intra-hospital regimen and with the checking of the resulting lists again when there is a transition in the treating service. There will be a definitive list of the medications that will be received by the patient after discharge, including an education intervention given to the patient and/or caregiver, and the communication of said information to the general ambulatory physician and specialists $[10,12,13]$.

This process consists of four steps: (1) creation of the pharmacological record during the initial contact with the patient; (2) the confirmation of the information with as many sources as it is possible to get for it; (3) then a conciliation of the corresponding list with the prescribed medication being taken at that moment of the patient's care happens; (4) last, but not least, it must be ensured that in the transmission of information all healthcare providers. In summary, establish the pharmacological background during the first contact with the patient, which should include all the medication that has been prescribed by all the physicians involved in the patient's care, the over-the-counter medication taken by the patient and even the nutritional supplements or herbal preparations 
that the patient has become accustomed to receive [26-28].

After this follows the confirmation of the information, with as many sources as there are available for it: medical background, guardians, pharmacy and formulas to ensure that the information is current, exact and thorough.

Then it must be preceded towards the conciliation of the aforementioned list with the medications prescribed during a particular moment of care, correcting the mistakes if they are present. The list must be re-evaluated as many times as necessary, according to the transitions in care.

Last, but not least, the transmission of the information must be ensured once the patient is discharged to both the healthcare providers and to the patient and his/her caregivers.

Several medical error occurrences have been reported in these scenarios, between $5.3 \%$ and $50 \%$, depending on the population and the environment being studied. An incidence of 13 23\% of ARMs have been found within the following month after the patient's discharge from the hospital [9, 29]. It is important to clarify, however, that not all medical errors end in ARMs and not all ARMs constitute a medical mistake. Still, it is notable that medication errors significantly increase the risk of suffering ARMs [26].

The omission of indicated medication is also susceptible to correction with the use of the pharmacotherapeutic conciliation strategy, since in this case the coherence between the diagnoses and the subsequent formulation is revised.

In a research study, only $5 \%$ of discharged patients obtained a prescription without any errors of conciliation. These errors are described as: discrepancies among the prescribed medications from different healthcare providers and what is received by the patient in the end [10].

In a European study done on patients at the moment of discharge, it was found that around $16 \%$ of prescriptions were unjustified and these prescriptions' direct cost was around 18,585 euros for a group of 557 patients; this without taking into account the indirect costs derived from the potential ARMs [30-38].

In the Clínica Universidad de La Sabana, in the year 2011, an observational study was carried out of the prescriptions of the patients while they were still hospitalized in the internal medicine unit and after being discharged. Pharmacotherapeutic conciliation was done and the following conclusions were underlined: the principal cause for medication error is omission. And the indications with the most errors in medication are: arterial hypertension and diabetes mellitus. It was discovered also that there is an overuse of anti-ulcerous medication both during hospitalization and after discharge, among other things.

With the results evidenced in this study, several recommendations were given out, and which are going to be mentioned next:

(1) All patients with four or more medications of chronic use must have a pharmacotherapeutic conciliation format at the moment of discharge;

(2) There must be a new entry done by internal medicine at the moment of admission of a patient to a hospitalization ward;

(3) A procedure for the administration of medication that is not covered by the obligatory health plan (NO POS) must be established with the nursing area;

(4) The study must be replicated in polymedicated patients of other medical specialties, such as neurology, neurosurgery and rehabilitation;

(5) The concordance between the diagnoses and the prescribed medication given during a hospitalization stay must be revised (revision of the medical records in a random way);

(6) A protocol of transition of care must be established to avoid errors (verification list);

(7) An epicrisis must be done per unit at the moment of transfer and at discharge;

(8) The printed prescriptions must be checked continuously;

(9) The discharge checklist must be annexed to the 
Table 3 Hospital checklist.

\begin{tabular}{|l|}
\hline I know the medication that I will continue to use after the hospitalization \\
\hline The medical prescriptions and special formats that I need to claim the medications were given to me \\
\hline I am clear as to when I have to return to consult my general physician or the specialist. \\
\hline I was handed the orders for new medical appointments and tests needed for these controls \\
\hline $\begin{array}{l}\text { I have a summary of my medical records where the diagnoses and treatments that were done for my information and that of my } \\
\text { physicians are consigned. }\end{array}$ \\
\hline $\begin{array}{l}\text { I have been informed about and understand the recommendations that I need to follow to be able to take care of myself, as well as the } \\
\text { signs of alarm to consult through the ER (emergency room). }\end{array}$ \\
$\begin{array}{l}\text { I have been informed about who I should contact in the hospital if I have questions or inconveniences, or if I need follow-up } \\
\text { appointments }\end{array}$ \\
\hline
\end{tabular}

Table 4 Distribution of the cases and costs of the study.

\begin{tabular}{|c|c|c|c|c|}
\hline No. & Cases & & & Costs in USD \\
\hline 1 & Indication & 57 & Indication & $\$ 95,933.19$ \\
\hline 2 & Non-adherence & 32 & Interaction & $\$ 63,878.98$ \\
\hline 3 & Dosage & 24 & Non-adherence & $\$ 59,768.75$ \\
\hline 4 & Administrative & 20 & Dosage & $\$ 48,899.87$ \\
\hline 5 & Interaction & 20 & Self-prescription & $\$ 46,032.67$ \\
\hline 6 & Self-prescription & 20 & Administrative & $\$ 29,864.57$ \\
\hline
\end{tabular}

pharmacotherapeutic conciliation format.

In a more recent study, an analysis was done on the PRMs (problems related with medications) that forced patients to consult through the emergency department and who required hospitalization for more than $48 \mathrm{~h}$ to handle these PRMs. An active search was carried out for those patients that consulted the ER (emergency room) department due to a PRM and that required hospitalization for more than $48 \mathrm{~h}$. From among the 230 PRMs identified, it was observed that approximately 130 of them appeared on patients with some form of co-morbidity (56.5\%). The co-morbidities most commonly found in this group of patients were: neurologic $15 \%$, diabetes $12.2 \%$, lung $13 \%$, cardiac $17 \%$, immunosuppression $5.7 \%$ and renal $3.9 \%$.

Likewise, it was evidenced that a little more than $50 \%$ of PRM cases appeared on polymedicated patients (with four or more medications of chronic use). The severity of the PRMs was defined as: lethal, three cases, severe, 20 cases, moderate, 205 cases and mild, only two cases.

PRMs were defined according to the criteria of predictability as: preventable and non-preventable, depending on the Hernández et al. [33] scoring. It was identified that the PRMs were $83 \%$ preventable and $17 \%$ non-preventable, in accordance with the different percentages reported in the literature [39-44].

During the follow-up done for approximately 10 months of 230 PRMs, it was estimated that these PRMs generated a cost of about $\$ 919,385,040$ COP (Colombian pesos), near to USD 334.000. Of this amount, \$717,485,749 COP corresponded to the management costs of preventable PRMs. And for the non-preventable PRMs, that in all cases were adverse reactions to medications, there was a cost of $\$ 195,141,311 \mathrm{COP}$.

\section{Conclusions}

There are diverse strategies to be able to implement the patient's safety from the point of view of the medication. One of the strategies used is the pharmacovigilance and the other is the pharmacotherapeutic conciliation [32, 33]. This last one begins with the creation of the pharmacological record at admission, it continues with the conciliation of the patient's regime during his stay in the hospital, checking the lists again when there is a transition of care, the preparation of a definitive list of all the medication that the patient will be receiving after being 
discharged and includes an education intervention of the patient and/or caregiver and the communication of said information to the general ambulatory physician and specialists. In our research the costs of PRM was $\$ 334,000$ for a set period of six months, $70 \%$ preventable, which warrants interventions to minimize the occurrence of PRM in ambulatory care. The following is the process to apply by different health professionals.

This process consists of four steps:

(1) Creation of the pharmacological record during the initial contact with the patient, which should include all the medication prescribed by all the physicians who have been involved in the patient's care, the over-the-counter medication consumed by the patient and even the nutritional supplements and herbal preparations he or she is accustomed to take;

(2) The confirmation of the information with as many sources as it is possible to get for it: clinical records, guardians, contacts, pharmacies and formulas to ensure that the information obtained is accurate, current, exact and thorough;

(3) Then a conciliation of the corresponding list with the prescribed medication being taken at that moment of the patient's care happens, correcting the mistakes if they are present and re-assessing the list as many times as necessary, depending on the transition of care;

(4) Last, but not least, it must be ensured that in the transmission of information all healthcare providers as well as the patient and the caregivers are included once the patient is discharged,

\section{References}

[1] WHO (World Health Organization Pharmacovigilance). 2016. "Pharmacovigilance." WHO. Accessed December 15, 2016. http://www.who.int/medicines/areas/quality_saf ety/safety_efficacy/pharmvigi/en/.

[2] Bates, D. W., Cullen, D. J., Laird, N., Petersen, L. A., Small, S. D., Servi, D., et al. 1995. "Incidence of Adverse Drug Events and Potential Adverse Drug Events. Implications for Prevention. ADE Prevention Study Group." JAMA 274: 29-34.

[3] Lazarou, J., Pomeranz, B. H., and Corey, P. N. 1998. "Incidence of Adverse Drug Reactions in Hospitalized
Patients: A Meta-analysis of Prospective Studies." JAMA 279: 1200-5.

[4] Comite de Consenso GIAF-UGR, GIFAF-USE, GIF-UGR. 2007. "Third Consensus of Granada on Drug Related Problems (DRP) and Negative Outcomes associated with Medication (NOM)." Ars. Pharm. 48 (1): 5-17.

[5] Bates, D. W., Spell, N., Cullen, D. J., Burdick, E., Laird, N., and Petersen, L. A. 1997. "The Costs of Adverse Drug Events in Hospitalized Patients. Adverse Drug Events Prevention Study Group.” JAMA 307: 307-11.

[6] Zed, P. J., Abu-Laban, R. B., Balen, R. M., Loewen, P. S., Hohl, C. M., Brubacher, J. R., et al. 2008. "Incidence, Severity and Preventability of Medication-Related Visits to the Emergency Department: A Prospective Study." CMAJ 178 (12): 1563-9.

[7] Leape, L. L., Bates, D. W., Cullen, D. J., Cooper, J., Demonaco, H. J., Gallivan, T., et al. 1995. "Systems Analysis of Adverse Drug Events. ADE Prevention Study Group." JAMA 274: 35-43.

[8] Forster, A. J., Clark, H. D., Menard, A., Dupuis, N., Chernish, R., Chandok, N., et al. 2004. "Adverse Events among Medical Patients after Discharge from Hospital." CMAJ 170: 345-9.

[9] Forster, A. J., Murff, H. J., Peterson, J. F., Gandhi, T. K., and Bates, D. W. 2003. "The Incidence and Severity of Adverse Events Affecting Patients after Discharge from the Hospital." Ann. Intern. Med. 138: 161-7.

[10] Coleman, E. A., Smith, J. D., Raha, D., and Min, S. J. 2005. "Posthospital Medication Discrepancies: Prevalence and Contributing Factors." Arch. Intern. Med. 165: 1842-7.

[11] Bell, C. M., Bajcar, J., Bierman, A. S., Li, P., Mamdani, M. M., and Urbach, D. R. 2006. "Potentially Unintended Discontinuation of Long-Term Medication Use after Elective Surgical Procedures." Arch. Intern. Med. 166: 2525-31.

[12] Delgado Sánchez, O., Anoz Jiménez, L., Serrano Fábia, A., and Nicolas Pico, J. 2007. "Conciliación de la Medicación.” Med. Clin. (Barc) 129: 343-8.

[13] Page II, R. L., Linnebur, S. A., Bryant, L. L., and Ruscin, J. M. 2010. "Inappropriate Prescribing in the Hospitalized Elderly Patient: Defining the Problem, Evaluation Tools, and Possible Solutions." Clin. Interv. Aging 5: 75-87.

[14] Campbell, F., Karnon, J., Czoski-Murray, C., and Jones, R. 2007. A Systematic Review of the Effectiveness and Cost-Effectiveness of Interventions Aimed at Preventing Medication Error (Medicines Reconciliation) at Hospital Admission. Sheffield: University of Sheffield.

[15] The Health Foundation. 2012. Evidence Scan: Reducing Prescribing Errors. London: The Health Foundation.

[16] Michels, R. D., and Meisel, S. B. 2003. "Program Using Pharmacy Technicians to Obtain Medication Histories." 
Am. J. Health Syst. Pharm. 60 (19): 1982-6.

[17] Rozich, J. D., Howard, R. J., Justeson, J. M., Macke, P. D., Lindsay, M. E., and Resar, R. K. 2004. "Standardization as a Mechanism to Improve Safety in Health Care." Jt. Comm. J. Qual. Patient Saf. 30: 5-14.

[18] Whittington, J., and Cohen, H. 2004. "OSF Healthcare's Journey in Patient Safety." Qual. Manag. Healthcare 13 (1): 53-9.

[19] Nickerson, A., MacKinnon, N. J., Roberts, N., and Saulnier, L. 2005. "Drug-Therapy Problems, Inconsistencies and Omissions Identified during a Medication Reconciliation and Seamless Care Service." Healthc Q. 8: 65-72.

[20] Otero, M. J., and Bajo Bajo, A. 1999. "Avoidance of Adverse Events Induced by Drugs Detected in an Emergency Department.” Rev. Clin. Esp. 199: 796-805. (in Spanish)

[21] Leape, L. L. 1995. "Preventing Adverse Drug Events." Am. J. Heath-Syst. Pharm. 52: 379-82

[22] Quality Interagency Coordination Task Force. 2000. Doing What Counts for Patient Safety: Federal Actions to Reduce Medical Error and Their Impact. Report of the QulC, Febrero.

[23] Manasse, H. R. 1989. "Medication Use in an Imperfect World: Drug Misadventuring as an Issue of Public Policy, Part 1." Am. J. Hosp. Pharm. 46: 929-44.

[24] Institute of Medicine. 1999. To Err Is Human: Building a Safer Health System. Washington, D.C.: National Academy Press.

[25] Garcia, J. C. 2015. "Patient Pharmaco-Safety from Medication." Vitae. Supl. 1: S56-8.

[26] Muñoz, M. J., Ayani, I., Rodríguez-Sasiain, M. J., Gutierrez, G., and Aguirre, C. 1998. "Monitoring in an Emergency Department of Adverse Reactions Caused by Medications in Children and Adults." Med. Clin. 111: 92-8. (in Spanish)

[27] Routledge, P. A., O’Mahony, M. S., and Woodhouse, K. W. 2003. "Adverse Drug Reactions in Elderly Patients." Br. J. Clin. Pharmacol. 57 (2): 121-6.

[28] Hafner, J. W., Belknap, S. M., Squillante, M. D., and Bucheit, K. A. 2002. "Adverse Drug Events in Emergency Department Patients.” Ann. Emerg. Med. 39: 258-67.

[29] Lazarou, J., Pomeranz, B. H., and Corey, P. N. 1998. "Incidence of Adverse Drug Reactions in Hospitalized Patients. A Meta-analysis of Prospective Studies." JAMA 279: 1200-5.

[30] Beijer, H. J. M., and De Blaey, C. J. 2002. "Hospitalisations Caused by Adverse Drug Reactions (ADR): A Meta-ánalysis of Observacional Studies." Pharmacy World \& Science 24: 46-54.

[31] Calderon, C. A. 2010. "Pharmacovigilance in the Last 10
Years: Update of Concepts and Classifications. Achievements and Challenges for the Future in Colombia." MéD.UIS. 24: 57-73. (in Spanish)

[32] Einarson, T. R. 1993. "Drug Related Hospital Admissions." Am. Pharmacother 27 (7-8): 832-40.

[33] Hernández, P. A., López, M. J. O., and Fernández, J. A. M. 2002. "Hospital Revenue Caused by Drugs: Incidence, Characteristics and Cost." Farm. Hosp. 26 (2): 77-89. (in Spanish)

[34] Tafreshi, M. J., Melby, M. J., Kaback, K. R., and Nord, T. C. 1999. "Medication Related Visits to the Emergency Department: A Prospective Study." Ann. Pharmacother. 33: $1252-7$.

[35] Tuneu, L., García-Pelaez, M., Lopez, S., Serra, G., Alba, G., De Irala, C., et al. 2000. "Drug-Related Problems in Patients Visiting an Emergency Room." Pharm. Care Esp. 2 (3): 177-92. (in Spanish)

[36] Rottenkolber, D., Schmiedl, S., Rottenkolber, M., Farker, K., Saljé, K., Mueller, S., et al. 2011. "Adverse Drug Reactions in Germany: Direct Costs of Internal Medicine Hospitalizations." Pharmacoepidemiol Drug Saf. 20 (6): 626-34.

[37] Chan, A., Lee, H., Ho, C., Cham, T. M., and Lin, S. J. 2008. "Cost Evaluation of Adverse Drug Reactions in Hospitalized Patients in Taiwan: A Prospective, Descriptive, Observational Study." Current Therapeutic Research 69: 118-29.

[38] Rodriguez-Monguio, R., Otero, M. J., and Rovira, J. 2003. "Assessing the Economic Impact of Adverse Drug Effects." Pharmacoeconomics 21 (9): 623-50.

[39] Briggs, A. H., and Levy, A. R. 2006. "Pharmacoeconomics and Pharmacoepidemiology Curious Bedfellows or a Match Made in Heaven?." Pharmacoeconomics 24 (11): 1079-86.

[40] Jiron, M. 2011. "Applications of Pharmacoepidemiology in Health Decision-Making." Rev. Farmacol. Chile 4 (1): 13-14. (in Spanish)

[41] Patterson, M., Laupacis, A., Bassett, K., Anderson, G. M., and BC-Ontario Pharmacosurveillance for Decision-Making Collaborative. 2006. "Using Pharmacoepidemiology to Inform Drug Coverage Policy: Initial Lessons from a Two-Province Collaborative." Health Affairs 25 (5): 1436-43.

[42] Hennessy, S. 2006. "Use of Health Care Databases in Pharmacoepidemiology." Basic \& Clinical Pharmacology \& Toxicology 98: 311-3.

[43] Herrera, M. 2000. "Pharmacoeconomics. Evaluation of the Efficiency in the Pharmacological Treatments." Rev Cubana Farm. 34 (1): 63-9. (in Spanish)

[44] NICE (National Institute for Clinical Excellence). 2016. "Glossary." NICE. Accessed December 15, 2016. http://www.nice.org.uk/website/glossary/. 